\title{
REVIEWS.
}

\section{A MANUAL OF SURGERY FOR INURSES.}

By Charles Wells, M.B., F.R.C.S. E. \& S. Livingstone. Edinburgh. 1938. Price 10/6.

In the Preface the Author says that he has attempted to present the subject matter to student nurses who have not had a preliminary training such as medical students undergo. Therefore perhaps it is only natural that the various sections are dealt with in a somewhat scrappy manner. The book might be described as "potted surgery," but as a text-book for nurses it leaves a good deal to be desired. Sometimes the English is a little obscure and unfortunate. As an example: the Author obviously means that the operation of thoracoplasty is one that is liable to produce much shock. That is an entirely different thing from writing " the operation is severe and all the more shocking for needing to be done in seriously ill patients".

Another criticism that we should like to make is that as much notice is taken of many very rare diseases as of the ordinary simple ones, and in some instances these rare diseases have a priority of description. We cannot help thinking that this is a mistake, as nurses, for some illogical reason, are likely to remember all about rare diseases which they have never seen, and forget the common ones of every-day life. As an example : in the section on "Diseases of the Liver," Tropical Abscess, Actinomycosis and Portal Phlebitis are first mentioned.

We also think that there is a lack of precise directions for ordinary surgical nursing of complications that may occur. For instance; in tonsillectomy, primary hæmorrhage is mentioned as the great danger, but no directions are given to the nurse should such an accident occur before medical aid can be obtained. This lack of specific direction is noticeable, and where given is sometimes misleading. Many surgeons dislike using a gauze wick for drainage purposes, nor do we believe that in a septic wound time limits should be given for removal of the tube. As another example, when discussing high pressure sterilising matters, we consider that nurses should be warned not to pack drums too tight. This is a practical thing that nurses should know, and few do.

Also we think that terms are used of which insufficient explanation is given. For instance, right at the beginning, the word "granulomatous" is used frequently, but a nurse reading this book for the first time (or for that matter even at an advanced stage of her career) would have no clear conception of what "granulomatous" means, and the same is true of other terms. Nurses are very prone to use technical terms without a full comprehension of their meaning, and an explanation of any technical term should surely be given, especially in an elementary book such as this is meant to be. On page 64 the Author states that a clot travels to the lung as an "infarct.. .." There is no explanation of what an "infarct" is, and perhaps it is as well, as it is used here in a wrong sense.

The chapter on the "Eye" is excellent. It is a clear account of the elementary anatomy and pathology of the common diseases of the eye, and should be of great value.

The book will probably have a useful place for revision purposes for nurses going up for their final examinations, or for quick reference purposes. As a text-book, it is in some wavs too comprehensive, and in others not sufficiently so.

The book is adequately illustrated and well printed, but there are misprints at the bottom of page 252 and on page 266.

\section{PAGET'S DISEASE OF THE NIPPLE.}

By Keith Inglis. Oxford Medical Publications. 1936. Pp. 233. Price 36/-.

The author of this book has investigated in detail Paget's disease of the nipple together with certain other conditions considered to be early neoplastic states of surface epithelium for purposes of comparison and contrast. Inglis has come to the conclusion that this disease is a surface cancer commencing at the junction of lactiferous duct with epidermis or in a lactiferous duct near its outlet. The growth 